\title{
Evidence for Pre- to Postsynaptic Mismatch of the Cardiac Sympathetic Nervous System in Ischemic Congestive Heart Failure
}

\author{
James H. Caldwell ${ }^{1,2}$, Jeanne M. Link ${ }^{2}$, Wayne C. Levy ${ }^{1}$, Jeanne E. Poole ${ }^{1}$, and John R. Stratton ${ }^{3}$ \\ ${ }^{I}$ Division of Cardiology, Department of Medicine, University of Washington, Seattle, Washington; ${ }^{2}$ Department of Radiology, \\ University of Washington, Seattle, Washington; and ${ }^{3}$ Division of Cardiology, Department of Medicine, VA Medical Center \\ and University of Washington, Seattle, Washington
}

\begin{abstract}
Pre- and postsynaptic cardiac sympathetic function is altered in ischemic congestive heart failure (CHF). Whether there is a presynaptic-to-postsynaptic mismatch or whether mismatch is related to adverse cardiac events is unknown. Methods: In 13 patients with ischemic CHF and 25 aged-matched healthy volunteers, presynaptic function was measured by PET of ${ }^{11} \mathrm{C}$ meta-hydroxyephedrine ( $\left.{ }^{11} \mathrm{C}-\mathrm{mHED}\right)$, a norepinephrine (NE) analog. Postsynaptic function, $\beta$-adrenergic receptor (BAR) density $\left(\mathrm{B}_{\max }^{\prime}\right)$, was measured by imaging ${ }^{11} \mathrm{C}-\mathrm{CGP} 12177$. Myocardial blood flow (MBF) was measured by imaging ${ }^{15} \mathrm{O}$-water. Each heart was analyzed both globally and regionally, excluding infarcted regions, and a mismatch score, defined as the ratio of $\mathrm{B}_{\text {max }}^{\prime}$ to NE uptake ( $\left.P S_{n t}\right)$, was used to indicate mismatch of post- and presynaptic function. Results: Global and regional MBF was not different between CHF and healthy subjects. The global measure of $\mathrm{PS}_{\mathrm{nt}}$ was lower in $\mathrm{CHF}(0.32 \pm 0.34)$ than that in healthy subjects $(0.81 \pm 0.33, P<0.0001)$ and in all 12 regions. Global $\mathrm{B}_{\text {max }}^{\prime}$ tended to be lower in $\mathrm{CHF}$ than that in healthy subjects $(10.0 \pm 6.4 \mathrm{pmol} / \mathrm{mL}$ vs. $13.4 \pm 4.2, P=0.056)$ and in all 12 regions. The global mismatch score $\left(B_{\text {max }}^{\prime}: \mathrm{PS}_{\mathrm{nt}}\right)$ in $\mathrm{CHF}$ patients was significantly greater than that in healthy subjects (50.3 \pm 50.7 vs. $19.3 \pm 9.7, P=0.005)$ and also greater in 11 of 12 regions. After $1.5 \mathrm{y}$ of follow-up, 4 individuals had an adverse outcome (CHF death, new or recurrent sudden death, or progressive CHF leading to transplantation). Three of the 4 had mismatch scores $>3$ times that of the healthy subjects or the CHF patients without an adverse outcome. Conclusion: Mismatch between pre- and postsynaptic left ventricular sympathetic function is present in patients with severe CHF and may be more marked in those with adverse outcomes.
\end{abstract}

Key Words: imaging heart failure; sudden death; sympathetic nervous system

J Nucl Med 2008; 49:234-241

DOI: 10.2967/jnumed.107.044339

Received Jun. 19, 2007; revision accepted Oct. 25, 2007.

For correspondence or reprints contact: James H. Caldwell, MD, Nuclear Medicine, Box 356113, University of Washington, Seattle, WA 98195.

E-mail: jcald@u.washington.edu

COPYRIGHT ( 2008 by the Society of Nuclear Medicine, Inc.
$\mathbf{S}$ ympathetic function is abnormal in congestive heart failure (CHF) patients, who demonstrate increased sympathetic nerve activity, norepinephrine (NE) plasma levels, cardiac NE spillover, and depleted cardiac NE stores (1-4). This increased cardiac adrenergic drive may involve increased neuronal NE release, decreased efficiency of NE reuptake by the NE transporter (NET-1), or reduced vesicular storage (57). In animals, regional heterogeneity of sympathetic nervous system (SNS) function and reenervation has been observed in myocardial infarct borders $(8-10)$. Such regional heterogeneities may cause or exacerbate arrhythmias.

Regional heterogeneity of ${ }^{11} \mathrm{C}$-meta-hydroxyephedrine $\left({ }^{11} \mathrm{C}-\mathrm{mHED}\right)$ uptake and retention has been demonstrated in patients with coronary artery disease (CAD) and ventricular tachycardia/fibrillation and hypothesized to increase risk for sudden cardiac death (SCD) (11). Heterogeneity of ${ }^{11} \mathrm{C}-\mathrm{mHED}$ was also observed in patients with left ventricular (LV) dysfunction (12-14). In nonischemic dilated cardiomyopathy, marked regional variation in ${ }^{11} \mathrm{C}$-mHED uptake correlated with variations in tissue NE reuptake density from explanted, diseased hearts (15).

$\beta$-Adrenergic receptor (BAR) density is decreased in both ischemic and nonischemic CHF compared with agematched healthy subjects $(2,3,16)$. PET has shown that global BAR density is lower in patients with CHF from idiopathic dilated cardiomyopathy (IDCM) compared with that of healthy subjects (17).

In humans with arrhythmogenic right ventricular dysplasia, which predisposes to fatal arrhythmias, there is a marked $(\sim 40 \%)$ reduction of postsynaptic $\beta$-receptor density and a lesser decrease in presynaptic function (18). This possible imbalance in pre- and postsynaptic function can be termed a mismatch and is likely to also be present in CHF. The purpose of this study was to determine the extent and magnitude of regional mismatch between pre- and postsynaptic function in patients with ischemic CHF in comparison with that of age-matched healthy subjects and to relate mismatch to adverse events during follow-up. 


\section{MATERIALS AND METHODS}

The 2 populations studied were patients with CAD and CHF from depressed LV function and healthy older volunteers. Twentyfive healthy sedentary volunteers (mean age $\pm \mathrm{SD}, 72.0 \pm 3.6 \mathrm{y}$; range, 65-79 y) were studied. The healthy volunteers were screened to exclude current smoking, hypertension, chronic medication use, or any cardiovascular or pulmonary disease. All had unremarkable blood counts and chemistries, including cholesterol and thyroid-stimulating hormone, urinalysis, normal 2-dimensional and Doppler echocardiograms for age, and normal maximal postexercise SPECT ${ }^{99 \mathrm{~m}} \mathrm{Tc}$-sestamibi images. Thirteen were female (mean age, $71.3 \pm 3.6 \mathrm{y}$ ) and 12 were male (age, $72.2 \pm 3.8 \mathrm{y}$ ). All females were receiving hormone replacement therapy.

The CHF subjects (Table 1) consisted of 13 male patients (mean age \pm SD, $69.8 \pm 5.6 \mathrm{y}$; range, 60-75 y; $P=$ not significant [NS] vs. healthy subjects) with CAD and an LV ejection fraction $(\mathrm{EF}) \leq 45 \%$ by catheterization or 2-dimensional echocardiography (mean EF, 32\% $\pm 9 \%$ ). Seven patients had implanted defibrillators because of a previous episode of symptomatic, sustained ventricular tachycardia or ventricular fibrillation $>6$ wk before the PET study. Eight subjects were on chronic $\beta$-blocker therapy (mean dose, $96 \pm 68 \mathrm{mg}$ metoprolol daily), which was withheld for $>24 \mathrm{~h}$ before imaging. Other medications (Table 1) were taken as usual. No patient was taking medications known to directly affect presynaptic sympathetic function.

This study was approved by the University of Washington Human Subjects, Radioactive Drug Research, and Radiation Safety Committees. All subjects gave written informed consent.

\section{Study Protocol}

Radiotracer Synthesis. ${ }^{15} \mathrm{O}-$ Water (19), ${ }^{11} \mathrm{C}-\mathrm{mHED}$ (20), and the BAR antagonist $(S)-(-)-{ }^{11} \mathrm{C}-\mathrm{CGP} 12177\left((S)-4-\left(3^{\prime}-t\right.\right.$-butylamino$2^{\prime}$-hydroxypropoxy)-benzimidazol-2- ${ }^{11} \mathrm{C}$-one $),{ }^{11} \mathrm{C}$-CGP12177 $\left({ }^{11} \mathrm{C}\right.$ CGP) (21-23), were synthesized according to published methods.

Metabolites of ${ }^{11} \mathrm{C}-\mathrm{mHED}$ were measured as reported (24). (S)(-)-CGP is not metabolized in humans (25). The amount of nonradioactive material in the ${ }^{11} \mathrm{C}$-CGP and the ${ }^{11} \mathrm{C}$-mHED injectates was measured using high-performance liquid chromatography
(HPLC) with mass spectrometry (MS) (ES+) detection (Waters 2190 and Micromass ZMD) (14).

Imaging Protocol. Heart rate and blood pressure were monitored continuously and recorded each minute from $5 \mathrm{~min}$ before to $15 \mathrm{~min}$ after each radiotracer injection. The subjects were positioned in the tomograph (Advance; GE Healthcare) using 1-min transmission scans to localize the heart (35 planes, $15 \mathrm{~cm})$. Twenty-minute transmission scans were acquired using a rotating ${ }^{68} \mathrm{Ge}$ rod source. The imaging protocol (Fig. 1) consisted of sequential injections of high-specific-activity (SA) $(3.7 \mathrm{MBq} / \mathrm{kg}$ average, $\left.2.76 \times 10^{7} \mathrm{mBq} / \mathrm{mmol}\right){ }^{11} \mathrm{C}$-CGP followed approximately $20 \mathrm{~min}$ later by injection of $3.7 \mathrm{MBq} / \mathrm{kg}$ low SA (average, $2.23 \times$ $10^{6} \mathrm{MBq} / \mathrm{mmol}$ ) ${ }^{11} \mathrm{C}-\mathrm{CGP}$ as described previously (26) followed by ${ }^{15} \mathrm{O}$-water and ${ }^{11} \mathrm{C}$-mHED. Activity $(\mathrm{mCi})$ of each injectate was measured using a calibrated ion chamber.

For the first CGP injection, dynamic PET images $(60 \mathrm{~s} \times 1,5 \mathrm{~s} \times$ $2,10 \mathrm{~s} \times 6,15 \mathrm{~s} \times 6,30 \mathrm{~s} \times 4,60 \mathrm{~s} \times 15$ ) were acquired for 21 min (Fig. 1), starting $1 \mathrm{~min}$ before the first CGP injection (CGP1). Low SA CGP (CGP2) was injected $\sim 25 \mathrm{~min}$ after the CGP1 injection. The CGP1 dynamic image sequence was repeated and continued for $45 \mathrm{~min}$ by adding 5-min frames. Myocardial blood flow (MBF) was measured with a bolus injection of $18.5 \mathrm{MBq} /$ $\mathrm{kg}$ of ${ }^{15} \mathrm{O}$-water. Dynamic PET images were acquired for $5 \mathrm{~min}$. After $15 \mathrm{~min}$ for ${ }^{15} \mathrm{O}$ decay, ${ }^{11} \mathrm{C}-\mathrm{mHED}(7.4 \mathrm{MBq} / \mathrm{kg})$ was infused with the dynamic PET image acquisition sequence as for CGP2. The ${ }^{11} \mathrm{C}-\mathrm{CGP}$ and ${ }^{11} \mathrm{C}$-mHED were injected over $1 \mathrm{~min}$. Subjects were in the tomograph for the entire imaging protocol. Heparinized plasma samples from $\sim 5,10,20,30$, and $40 \mathrm{~min}$ after ${ }^{11} \mathrm{C}$-mHED injection were analyzed for ${ }^{11} \mathrm{C}-\mathrm{mHED}$ and metabolites (24).

The dynamic PET image sets were reconstructed, reoriented into short-axis cardiac projections, and analyzed. Images were decay-corrected to the time of each radiotracer injection, except for the CGP2 images, which were corrected to the start of the CGP1 injection. Myocardial and left atrial (LA) regions of interest (ROIs) were placed on static short-axis images from each set. These ROIs were applied to the dynamic images and time-activity curves generated for 3 middle LA planes and 96-128 myocardial

TABLE 1

Clinical Characteristics of CHF Subjects

\begin{tabular}{|c|c|c|c|c|c|c|c|c|c|}
\hline Age $(y)$ & $\mathrm{EF}$ & CAD & MI & NYHA class & ICD & Amiodarone & $\beta$-Blocker & ACEI or ARB & Event \\
\hline 75 & 0.35 & $1 \mathrm{vd}$ & & 3 & $x$ & $x$ & $X$ & $X$ & \\
\hline 76 & 0.40 & $3 v d$ & & 3 & $X$ & & $X$ & $X$ & \\
\hline 75 & 0.45 & & 1 & 3 & $X$ & & $X$ & $X$ & \\
\hline 67 & 0.12 & $3 v d$ & & 3 & & $X$ & & $X$ & SCD \\
\hline 61 & 0.35 & $3 v d$ & & 2 & & & & $x$ & \\
\hline 67 & 0.21 & & A & 4 & $\mathrm{X}$ & $\mathrm{X}$ & & $\mathrm{X}$ & Tx \\
\hline 73 & 0.34 & & 1 & 2 & $x$ & & & $x$ & \\
\hline 66 & 0.30 & & I & 4 & $x$ & $X$ & & $X$ & $\mathrm{CHF}$ \\
\hline 77 & 0.35 & & A & 2 & & & $x$ & $\mathrm{X}$ & SCD \\
\hline 67 & 0.23 & & $A$ & 4 & & & $X$ & $X$ & \\
\hline 61 & 0.36 & $2 v d$ & $A, L$ & 2 & & & $\mathrm{X}$ & $\mathrm{x}$ & \\
\hline 76 & 0.40 & $2 v d$ & & 3 & & & $X$ & $X$ & \\
\hline 68 & 0.29 & $3 v d$ & 1 & 2 & $X$ & & $\mathrm{X}$ & $\mathrm{X}$ & \\
\hline
\end{tabular}

$\mathrm{EF}=$ ejection fraction; $\mathrm{CAD}=$ coronary artery stenosis of $>50 \%$ diameter stenosis; $\mathrm{Ml}=$ electrographic myocardial infarction $(\mathrm{I}=$ inferior, $\mathrm{A}=$ anterior, $\mathrm{L}=$ lateral); NYHA = New York Heart Association; ICD = implanted defibrillator; $\mathrm{ACEl}$ or ARB = angiotensinconverting enzyme inhibitor or angiotensin-receptor blocker; 1vd, 2vd, and 3vd = number of diseased vessels; SCD = new or recurrent ventricular fibrillation/ventricular tachycardia; $\mathrm{Tx}=$ transplanted; $\mathrm{CHF}=$ death from progressive $\mathrm{CHF}$. 


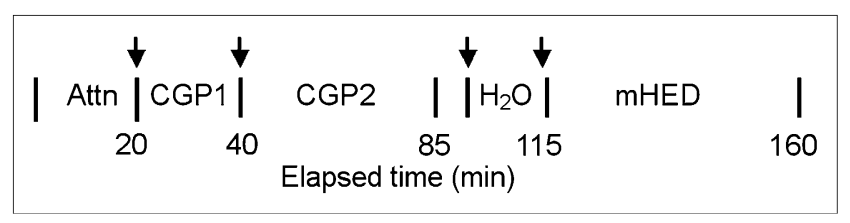

FIGURE 1. Time line for radiotracer injection (arrows) and PET image acquisition. Attn = transmission image acquisition; CGP1 = high-specific-activity ${ }^{11} \mathrm{C}$-CGP; CGP2 = low-specificactivity ${ }^{11} \mathrm{C}-\mathrm{CGP} ; \mathrm{H}_{2} \mathrm{O}={ }^{15} \mathrm{O}$-water.

ROIs per heart (12-16 slices starting at the apex depending on heart size and with 8 sectors per slice). Three LA planes were averaged to provide a single LA time-activity curve for each image set, which is used as the input function for the respective model analysis described below. The 3 most apical LV planes were excluded from analysis to avoid any partial-volume effect from this region. After quantitative analysis of the remaining individual ROIs, the slice data were averaged to give 3 cross-section slices labeled apical, mid, and basal. Then, 2 adjacent sector's ROIs were averaged to give 4 regions per slice: anterior, lateral, inferior, and septal. This resulted in 12 LV ROIs and a global ROI (average of the 12) per subject for each of the 4 radiopharmaceutical injections.

The ${ }^{15} \mathrm{O}$-water time-activity curves (cpm/pixel) from the LA and from each of the individual LV ROIs were modeled to obtain MBF (27). The ${ }^{11} \mathrm{C}-\mathrm{CGP}$ time-activity curve data were converted to $\mathrm{pmol} / \mathrm{mCi}$ at the time of first injection based on the SA of the injectate. Some of the $\mathrm{CHF}$ patients had prior myocardial infarctions (MIs) with thin walls. To minimize MI partial-volume effects, we excluded regions in which the resting MBF was $<0.16$ $\mathrm{mL} / \mathrm{min} / \mathrm{mL}$ from analysis. This is the lowest value for any single ROI in the 25 healthy subjects and 3.5 SD below the normal mean MBF. The low MBF ROIs were excluded before the summing of slices that gave the final 12 ROIs used for comparisons between pre- and postsynaptic function. Only $5 \%$ of 1,288 MBF ROIs were excluded from the $\mathrm{CHF}$ patients. This resulted in an average of $12.7 \pm 8.7$ excluded ROIs from 6 of 13 patients.

\section{Data Analysis}

${ }^{11} \mathrm{C}$-mHED metabolites, expressed as the fraction of the wholeblood activity, contribute to the blood PET signal (11). These fractions were curve fit to a rising time-dependent exponential function of the form, $\mathrm{f}(\mathrm{t})=\mathrm{y}^{0}+\left(\mathrm{a}^{*}\left(1-\exp \left(-\mathrm{b}^{*} \mathrm{t}\right)\right)\right)$ using SigmaPlot (SYSTAT Software). Using these derived values, a metabolite-corrected LA cavity time-activity curve was generated by multiplying the LA cavity activity by the function $(1-\mathrm{f}(\mathrm{t}))$. Representative metabolite-corrected and uncorrected LA timeactivity curves and a LV ROI time-activity curve from a healthy subject are shown in Figure 2.

${ }^{11} \mathrm{C}$-mHED kinetics were modeled by blood tissue exchange as previously described and uses the $\mathrm{MBF}$ value from the ${ }^{15} \mathrm{O}$-water study to provide the flow parameter in the model $(14,28)$. This model expresses ${ }^{11} \mathrm{C}$-mHED kinetics in terms of the permeability. surface area product $\left(\mathrm{PS}_{\mathrm{nt}}, \mathrm{mL} / \mathrm{min} / \mathrm{mL}\right.$ tissue) for ${ }^{11} \mathrm{C}-\mathrm{mHED}$ uptake into the nerve terminal from the interstitial space (ISF) through the NET-1 process and $\mathrm{PS}_{\mathrm{ves}}$ for release of ${ }^{11} \mathrm{C}-\mathrm{mHED}$ back into the ISF through exocytosis. The neuronal storage of ${ }^{11} \mathrm{C}-\mathrm{mHED}$ is expressed as a virtual volume $\left(\mathrm{V}_{\mathrm{nt}}^{\prime}, \mathrm{mL} / \mathrm{mL}\right.$ tissue $)$ and the rate of vesicular storage of mHED is expressed as $\mathrm{G}_{\mathrm{seq}}$ $(\mathrm{mL} / \mathrm{min} / \mathrm{mL})$. Transport rates and volumes are expressed as milliliter of tissue without conversion for any tissue density. The parameter $\mathrm{PS}_{\mathrm{nt}}$ most closely represents ${ }^{11} \mathrm{C}$-mHED uptake into the nerve by NET-1 and is the process most likely to be affected by myocardial ischemia or injury. BAR density $\left(\mathrm{B}_{\max }^{\prime}\right)$ was estimated for each myocardial ROI using the Delforge method $(26,29)$.

A mismatch score, defined as the ratio of $\mathrm{B}_{\max }^{\prime}$ to $\mathrm{PS}_{\mathrm{n}}$, is used to indicate mismatch of post- and pre-SNS function.

\section{Statistics}

Hemodynamic measurements, MBF, and SNS measures, $\mathrm{B}_{\max }^{\prime}$, $\mathrm{PS}_{\mathrm{nt}}, \mathrm{PS}_{\mathrm{ves}}, \mathrm{V}_{\mathrm{nt}}^{\prime}$, and $\mathrm{G}_{\mathrm{seq}}$ were compared between the healthy subjects and the CHF patients using a 2-tailed, unpaired Student $t$ test. Hemodynamic measurements before and after radiotracer injections were compared using paired $t$ tests. Statistical analyses used SPSS.

\section{RESULTS}

\section{Hemodynamics}

Heart rate and blood pressure before and during imaging are presented in Table 2. Five 1-min preinjection recordings were averaged as baseline for each injection. The greatest change in each measure within 0-15 min after injection was compared with the baseline data (Table 2). Compared with preinjection values, postinjection hemodynamics after CGP
FIGURE 2. Decay-corrected ${ }^{11} \mathrm{C}-\mathrm{mHED}$ time-activity curves from myocardial and metabolite left atrial cavity (LA Cav) ROIs in CHF patient with our model fit to myocardial time-activity curves. (Left) Location of ROI 8 (arrowhead), a visually "normal" region, and the corresponding myocardial time-activity curve. (Right) Location of ROI 3 , an abnormal mHED accumulation, is shown. ROls are bounded by inside and outside arcs within each of 8 radial lines. Parameter estimates are given for $\mathrm{PS}_{\mathrm{nt}}$, $\mathrm{PS}_{\text {ves }}\left({ }^{11} \mathrm{C}-\mathrm{mHED}\right.$ release by vesicles), $\mathrm{V}_{\mathrm{nt}}^{\prime}$ (virtual volume of nerve terminal), and $\mathrm{G}_{\text {seq }}$ (rate vesicular storage of $\mathrm{MHED}$ ). $\mathrm{MBF}$ and the retention fraction (RF) of ${ }^{11} \mathrm{C}-\mathrm{mHED}$ for the 2 ROls are also shown.

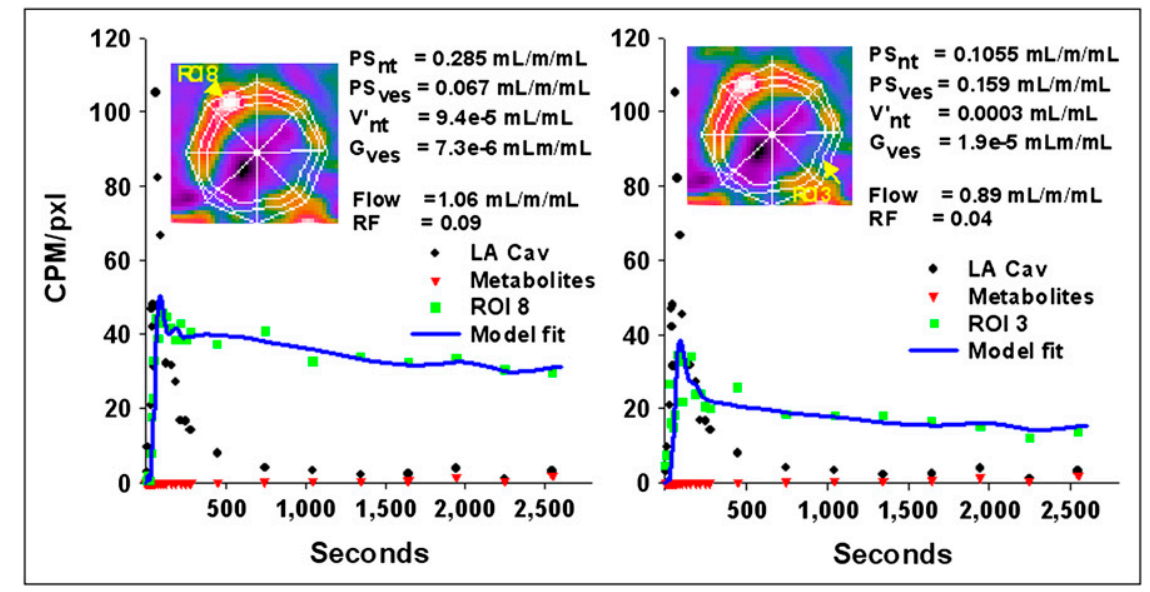


TABLE 2

Hemodynamics Before and After Radiotracer Injection

\begin{tabular}{|c|c|c|c|c|c|c|}
\hline \multirow{3}{*}{$\begin{array}{c}\text { Radiotracer } \\
\text { injection }\end{array}$} & \multicolumn{6}{|c|}{${ }^{11} \mathrm{C}-\mathrm{CGP} 1$} \\
\hline & \multicolumn{3}{|c|}{ Healthy subjects } & \multicolumn{3}{|c|}{ CHF patients } \\
\hline & $\mathrm{HR}^{*}$ & $\mathrm{SBP}^{*}$ & $\mathrm{DBP}^{*}$ & $\mathrm{HR}^{*}$ & $\mathrm{SBP}^{*}$ & $\mathrm{DBP}^{*}$ \\
\hline Before & $63.2 \pm 8.0$ & $147 \pm 15$ & $65.0 \pm 10.7$ & $74.7 \pm 14^{\dagger}$ & $139 \pm 30$ & $75.9 \pm 11.3^{\dagger}$ \\
\hline \multirow[t]{2}{*}{ After } & $60.9 \pm 8.9^{\ddagger}$ & $151 \pm 13^{\ddagger}$ & $65.9 \pm 8.8$ & $69.2 \pm 13.5^{\dagger}$ & $141 \pm 28$ & $75.8 \pm 13.2^{\dagger}$ \\
\hline & \multicolumn{6}{|c|}{${ }^{11} \mathrm{C}-\mathrm{CGP} 2$} \\
\hline Before & $63.4 \pm 8.7$ & $146 \pm 13$ & $63.9 \pm 9.5$ & $72.0 \pm 10.5^{\dagger}$ & $137 \pm 29$ & $73.2 \pm 11.4^{\dagger}$ \\
\hline \multirow[t]{2}{*}{ After } & $60.4 \pm 8.3^{\ddagger}$ & $151 \pm 12^{\ddagger}$ & $66.2 \pm 9.3^{\ddagger}$ & $68.1 \pm 9.2^{\dagger}$ & $140 \pm 30$ & $71.6 \pm 12.4$ \\
\hline & \multicolumn{6}{|c|}{${ }^{11} \mathrm{C}-\mathrm{mHED}$} \\
\hline Before & $62.2 \pm 8.6$ & $148 \pm 12$ & $65.0 \pm 10.2$ & $64.8 \pm 8.7 \S$ & $135 \pm 33$ & $68.2 \pm 14 \S$ \\
\hline After & $61.3 \pm 8.4$ & $152 \pm 12^{\ddagger}$ & $66.2 \pm 10.1$ & $66.9 \pm 8.6$ & $138 \pm 34^{\ddagger}$ & $73.1 \pm 15.5^{\ddagger}$ \\
\hline \multicolumn{7}{|c|}{$\begin{array}{l}\text { CGP1 and CGP2 }=\text { first and second }{ }^{11} \mathrm{C}-\mathrm{CGP} \text { injections; HR }=\text { heart rate; SBP }=\text { systolic blood pressure; DBP }=\text { diastolic blooc } \\
\text { pressure. } \\
{ }^{*} \text { Mean } \pm \text { SD. } \\
{ }^{\dagger} P \leq 0.05 \text { vs. healthy subjects, unpaired } t \text { test. } \\
{ }^{\ddagger} P \leq 0.05 \text { before vs. after, paired } t \text { test. } \\
{ }^{\$} P \leq 0.05 \text { vs. CGP1, paired } t \text { test. }\end{array}$} \\
\hline
\end{tabular}

injection in both healthy subjects and CHF patients were statistically different but not clinically significant.

\section{Images}

After excluding myocardial regions with $\mathrm{MBF}<0.16$ $\mathrm{mL} / \mathrm{min} / \mathrm{mL}$, the global average resting $\mathrm{MBF}$ was $0.76 \pm$ $0.20 \mathrm{~mL} / \mathrm{min} / \mathrm{mL}$ in the CHF patients vs. $0.78 \pm 0.15$ in the healthy subjects ( $P=\mathrm{NS}$; Fig. 3 ). MBF did not significantly differ for any of the 12 regions between healthy subjects and $\mathrm{CHF}$ patients, consistent with exclusion of infarcted tissue from the analyses.

Representative short-axis tomographic slices of ${ }^{11} \mathrm{C}$ mHED and ${ }^{11} \mathrm{C}-\mathrm{CGP}$ images (Fig. 4) are shown for a patient with an LV EF of 0.35 . For ${ }^{11} \mathrm{C}$-mHED, only the anterior-septal regions appear to have normal uptake. In contrast, the ${ }^{11} \mathrm{C}$-CGP images show uptake in all regions except for the site of a prior inferior MI.

Global $\mathrm{PS}_{\mathrm{nt}},{ }^{11} \mathrm{C}-\mathrm{mHED}$ nerve uptake by NET-1, was significantly lower for CHF patients $(0.32 \pm 0.34 \mathrm{~mL} / \mathrm{min} / \mathrm{mL})$ than that for healthy subjects $(0.81 \pm 0.33, P=0.0001) . \mathrm{PS}_{\mathrm{nt}}$ was lower and varied more between the 12 regions of the CHF patients compared with that of healthy subjects (Fig. 5). $\mathrm{PS}_{\mathrm{nt}}$ did not differ between subjects who did not take $\beta$-blockers and those who had them discontinued for $24 \mathrm{~h}$ before imaging.

Global $\mathrm{B}_{\max }^{\prime}$ was $22 \%$ lower in the CHF patients compared with that of healthy subjects (global, $10.0 \pm 6.4$ vs. $13.4 \pm 4.2 \mathrm{pmol} / \mathrm{mL})$, which was of borderline statistical significance $(P=0.056)$ (Fig. 3). Regional $\mathrm{B}_{\max }^{\prime}$ also tended to be lower (data not shown). Global $\mathrm{B}_{\max }^{\prime}$ did not differ between subjects who did not take $\beta$-blockers and those who had them discontinued for $24 \mathrm{~h}$ before imaging. This was expected, as the average plasma half-life of metoprolol is $3.5 \mathrm{~h}$.
The mismatch score was defined as the ratio of $\mathrm{B}_{\max }^{\prime}$ to $\mathrm{PS}_{\mathrm{nt}}$ and is used to indicate mismatch of post- and pre-SNS function. The global average mismatch score was significantly greater and more variable in the $\mathrm{CHF}$ patients than that in the healthy subjects $(50.3 \pm 50.7$ vs. $19.3 \pm 9.7$, $P=0.005)$. Regional mismatch scores for all 12 regions were significantly higher in the CHF patients than those in the healthy subjects (all $P<0.05$; Fig. 6).

The parameters $\mathrm{PS}_{\mathrm{ves}}$ and $\mathrm{G}_{\mathrm{seq}}$ did not differ between healthy subjects and CHF patients. The difference for mean $\mathrm{V}_{\mathrm{nt}}^{\prime}$ between the 2 populations was significant, but with large SD, and, thus, not physiologically meaningful. The parameters $\mathrm{V}_{\mathrm{nt}}^{\prime}, \mathrm{G}_{\mathrm{seq}}$, and $\mathrm{PS}_{\mathrm{ves}}$ are not independent. To

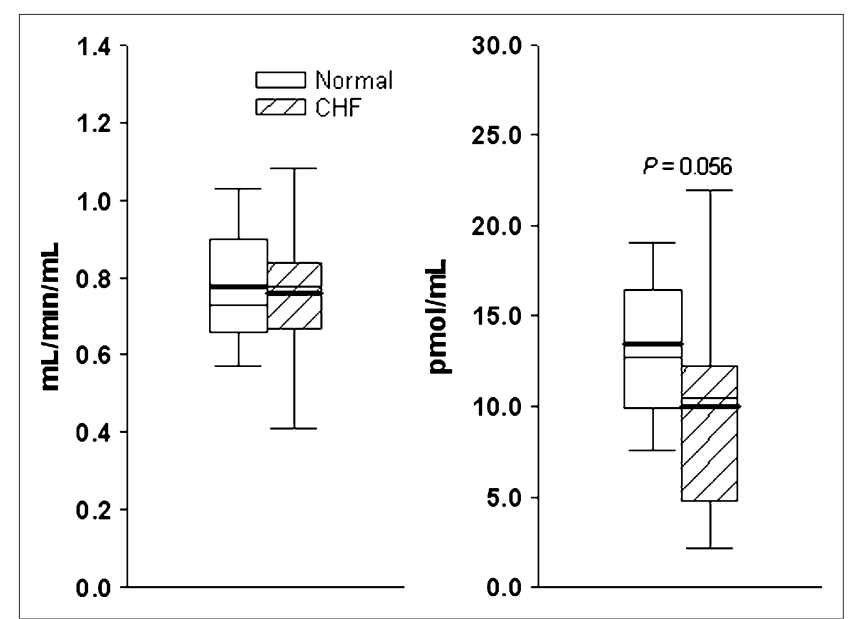

FIGURE 3. Box-and-whisker plots for global values for MBF (left) and $\mathrm{B}_{\max }^{\prime}$ (right) for healthy subjects (normal) and $\mathrm{CHF}$ patients. Box represents $25 \%-75 \%$ of data; whiskers represent $5 \%-95 \%$; heavy and thin solid lines are mean and median values, respectively. 
FIGURE 4. Short-axis PET images of ${ }^{11} \mathrm{C}-m$ HED (35- to 45 -min sum) and ${ }^{11} \mathrm{C}$ CGP (10- to 20-min sum from injection 1) in CHF patient. Apical slices are at upper left and basal slices are at lower right of each panel. Arrows indicate extensive mismatch between ${ }^{11} \mathrm{C}-\mathrm{mHED}$ and ${ }^{11} \mathrm{C}$ CGP.
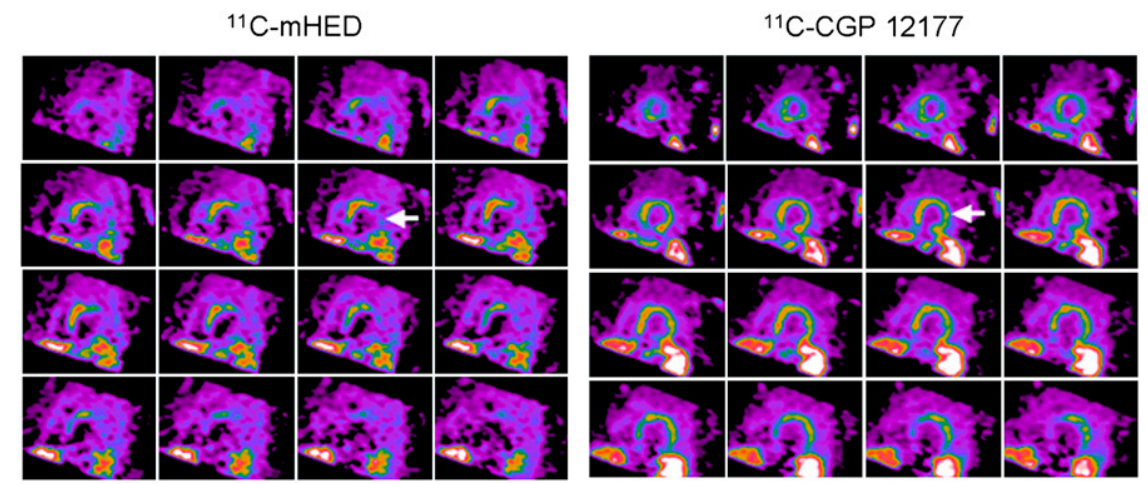

account for codependence, we examined the 3 parameters as a "lumped" parameter, LP:

$$
\mathrm{LP}=\frac{1}{\mathrm{~V}_{\mathrm{nt}}^{\prime}} \cdot \frac{\left(\mathrm{G}_{\mathrm{seq}} \cdot \mathrm{PS}_{\mathrm{ves}}\right)}{\left(\mathrm{G}_{\mathrm{seq}}+\mathrm{PS}_{\mathrm{ves}}\right)} .
$$

There was a nonsignificant trend for the global and regional LPs to be lower in CHF patients than that in healthy subjects. However, if we omitted either the LP or the 3 individual parameters, the model would not fit the myocardial ROI data, indicating that these parameters, though less physiologically sensitive than $\mathrm{PS}_{\mathrm{n}}$, are necessary for the model. Because the CHF population was all male, for all parameters, we then compared the $13 \mathrm{CHF}$ patients to just the 12 healthy males. The results were unchanged.

\section{Follow-up}

All CHF patients were followed for at least 18 mo. Four patients had an adverse event. One underwent cardiac transplantation for worsening CHF at 3 mo after the PET study. One died of progressive CHF 6 mo after PET. One patient without an implantable cardioverter-defibrillator (ICD), who previously had an episode of ventricular tachy-

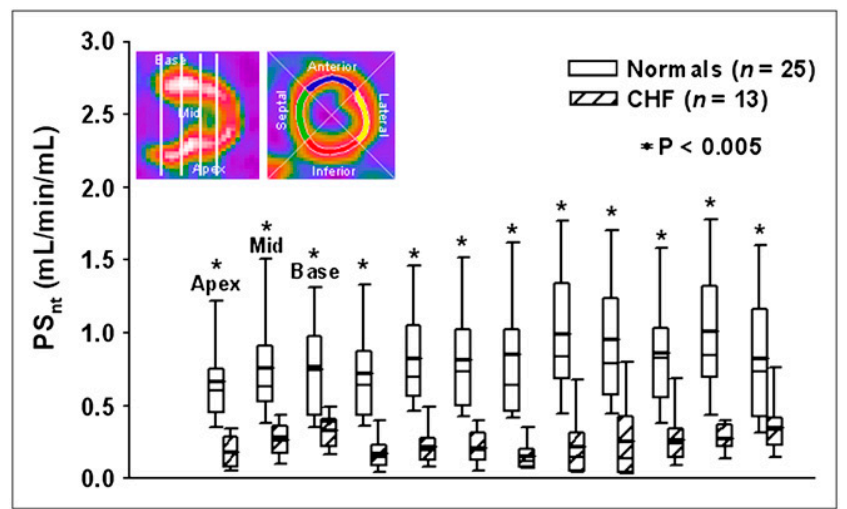

FIGURE 5. Box-and-whisker plots for regional NE transport $\left(\mathrm{PS}_{\mathrm{nt}}\right)$ for $12 \mathrm{LV}$ regions per subject. Locations of apical, middle, and basal slices lie between the white vertical bars on the longaxis image at upper left. Locations of large sectors-anterior, lateral, inferior, septal-are shown on short-axis image. Normals $=$ healthy subjects. cardia, suffered a recurrent episode for which he received an ICD. One patient without a prior history of arrhythmia but with an EF of 0.35 had an episode of nonresuscitable sudden death 6 wk after PET.

The mean and range of regional $\mathrm{B}_{\max }^{\prime}-$ to-PS $_{\mathrm{nt}}$ mismatch scores within each individual subject were compared in the healthy subjects and in subjects with and without adverse cardiac events. All 25 healthy subjects had close matching of pre- and postsynaptic function and none had an adverse event. In contrast, 3 of 4 patients with an adverse event had a mean mismatch score $>6 \mathrm{SD}$ above the mean of the healthy subjects (Fig. 7). Of the CHF patients with a mean mismatch score greater than the upper limit of normal $(2 \times$ SD), $43 \%$ had an adverse event. The same comparisons done using only the healthy males did not change the findings. Examination of individual heterogeneity of presynaptic function, $\mathrm{PS}_{\mathrm{nt}}$, or postsynaptic $\mathrm{B}_{\max }^{\prime}$ did not correlate with any of the individual patients with subsequent adverse events.

\section{DISCUSSION}

To our knowledge, this study is the first to demonstrate significant SNS mismatch between pre- and postsynaptic function in the same myocardial regions in patients with moderate-to-severe CHF. This study is also the first to

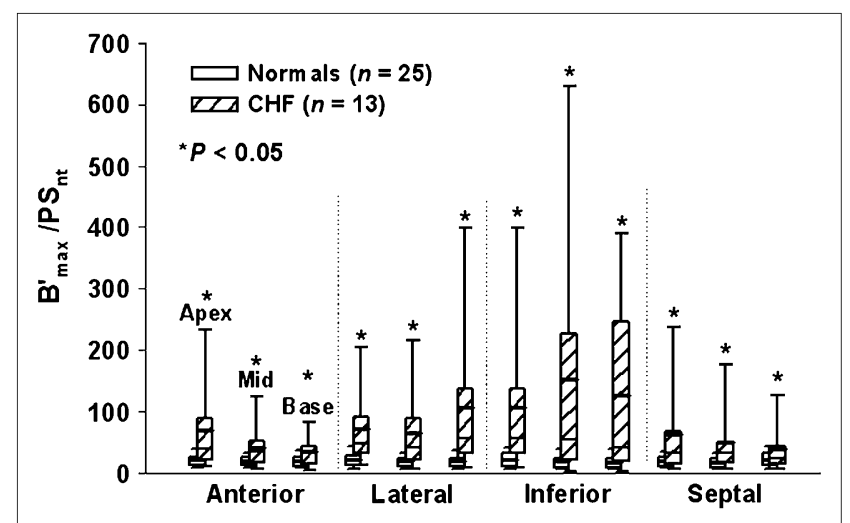

FIGURE 6. Box-and-whisker plots of mismatch score, which is the postsynaptic-to-presynaptic ratio $\left(B_{\text {max }}^{\prime}: P S_{n t}\right)$ for the same 12 LV regions as in Figure 5 . Normals = healthy subjects. 


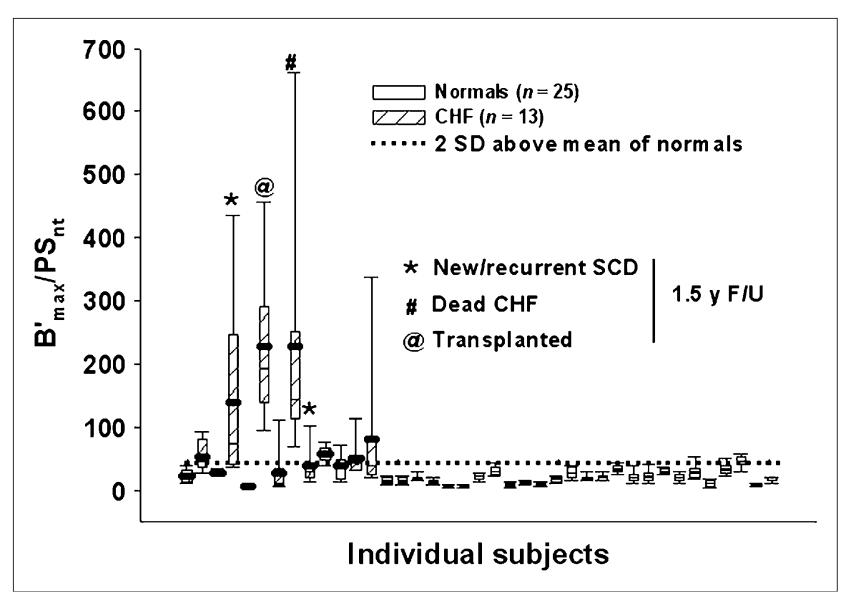

FIGURE 7. $\mathrm{B}_{\text {max }}^{\prime}: \mathrm{PS}_{\mathrm{nt}}$ from the 12 ROls per individual subject are displayed as box-and-whisker plots (mean = heavy solid line). The 5\%-95\% whiskers indicate within-subject $\mathrm{B}_{\text {max }}^{\prime}: \mathrm{PS}_{\mathrm{nt}}$ heterogeneity. Horizontal dotted line indicates 2 SD above the mean $\mathrm{B}_{\text {max }}^{\prime}: \mathrm{PS}_{\mathrm{nt}}$ of healthy subjects (normals). Patients with an adverse outcome at $1.5 \mathrm{y}$ of follow-up are indicated by the symbols shown.

demonstrate the potential of mismatch as a marker of adverse outcome in patients with CHF.

Our findings of decreased presynaptic function, measured by ${ }^{11} \mathrm{C}$-mHED imaging, in patients with ischemic CHF are consistent with previous reports $(13,30,31)$. Global $\mathrm{B}_{\max }^{\prime}$ was $22 \%$ lower in our CHF patients than that in the healthy subjects and was similarly decreased for all regions. Although not statistically significant, it is consistent with the $9 \%$ total (14\% for $\beta 1$ ) BAR density decrease from in vitro assays of biopsy samples of patients with ischemic CHF compared with age-matched healthy subjects (16). In another study, global PET BAR density was decreased in patients with CHF from idiopathic IDCM and correlated with biopsy samples in the same subjects (17).

A measure than can identify individuals rather than populations at high risk for future cardiac events is needed. Few studies have evaluated both pre- and postsynaptic function in the same individuals, and none have been previously done in a single day. Six patients with hypertrophic cardiomyopathy and normal LV function had decreased average LV ${ }^{11} \mathrm{C}$-mHED uptake (53\%) and BAR density (28\%) compared with that of healthy subjects (32). These authors postulated that decreased ${ }^{11} \mathrm{C}$-mHED uptake was due to impaired NET-1, which increased local catecholamines and downregulated BAR. Wichter et al. observed a $17 \%$ reduction in ${ }^{11} \mathrm{C}$-mHED uptake but a $42 \%$ reduction in average LV BAR density in 8 patients with arrhythmogenic RV cardiomyopathy compared with that of healthy subjects, suggesting considerable mismatch in this population (18). Ungerer et al. sampled tissue from explanted IDCM human hearts $(n=9)$ and found no correlation between pre- and postsynaptic function (BAR density); the noninvasive measure of ${ }^{11} \mathrm{C}$-mHED uptake did correlate with the in vitro measure of NET-1 $(r=0.65)$
(15). However, the tissue preparation they used measured total BAR density, not the surface-active receptors measured by ${ }^{11} \mathrm{C}$-CGP12177 imaging. They also found an inverse relationship $(r=-0.61)$ between BAR kinase1 ( $\beta$ ARK-1) and NET-1 binding and postulated that regional $\beta$ ARK-1 has a greater response to presynaptic stimulation than does BAR density. The suggestion from these prior studies is that both pre- and postsynaptic function is important but varies widely in disease.

Our results show that, both globally and regionally, BAR density and ${ }^{11} \mathrm{C}$-mHED uptake are tightly matched in healthy subjects, whereas patients with ischemic CHF have much greater global and regional mismatch by $\mathrm{B}_{\max }^{\prime}: \mathrm{PS}_{\mathrm{nt}}$ (Fig. 6). Increased BAR relative to partially functioning presynaptic sympathetic nerves could increase the arrhythmogenic potential by increasing the sensitivity of myocardial regions to increased NE levels, leading to local increases in the adenylyl-cyclase pathway and increased spontaneous depolarization or regional changes in sodium or potassium channel activity affecting repolarization.

The mechanism for the observed mismatch is unknown. The presynaptic component of the cardiac sympathetic nervous system is sensitive to ischemic insult $(9,33)$. In patients with ischemic CHF, we anticipate decreased or lost presynaptic innervation or abnormal NET-1 or NE storage or release. Sympathetic signaling in such regions would be more dependent on circulating catecholamines, which are probably lower than those in a normally functioning myoneural junction (3). This decrease could lead to BAR upregulation. BARs are not upregulated in the infarct but may be at the margins $(3,34,35)$. We excluded the most severely infarcted regions from analysis to minimize the partial-volume and spillover effect that would be present in the center of the infarct zones and likely to produce model estimates of both NE transport and BAR density when none exists. Outside the central infarct zone, impaired reuptake because of partial sympathetic nerve dysfunction could lead to excess local NE with a compensatory decrease in BAR density. Our data are consistent with observations of decreased, but not absent, presynaptic function in the periinfarct region combined with a small decrease in postsynaptic function $(16,36)$.

When studying mismatch, and mismatch heterogeneity, it is advantageous to study the smallest possible coregistered regions of sequential images. Our PET method approaches this goal. Regional mismatch (Fig. 6) is more striking than the global mismatch. In this small number of patients, the magnitude of mismatch was greatest in the lateral and inferior regions without any gradient between apex and base.

Not only do CHF patients have greater mismatch between presynaptic function and postsynaptic BAR density than that of healthy subjects, but our results suggest that individuals with the largest number of mismatch regions and the greatest magnitude of heterogeneity may be predisposed to an adverse event (Fig. 7). These findings are new. Previous studies of presynaptic function alone, using either methoxyisobutylisonitrile 
(MIBG) uptake and clearance or ${ }^{11} \mathrm{C}$-mHED retention fraction (RF) in CHF populations have suggested that those with the fastest MIBG washout or an RF $<0.18$ have a higher SCD or transplant event rate $(37,38)$. In our population, RF (not shown) and heterogeneity of presynaptic function (by RF or $\mathrm{PS}_{\mathrm{nt}}$ ) were not predictive. All but 1 of our subjects had an $\mathrm{RF}<0.18$ and that subject did not experience an event. The difference between our findings and others for presynaptic function may relate to patient populations or numbers. The previous studies contained a mixture of ischemic and nonischemic cardiomyopathies. Although the number of CHF patients in our study is too small to draw a conclusion, the mismatch data suggest that measures of heterogeneity of mismatch may be sensitive indicators of an individual's risk. Studies of a larger number of $\mathrm{CHF}$ patients, categorized as to etiology of $\mathrm{CHF}$ and with longer follow-up will be required to establish the prognostic value of mismatch of $\mathrm{B}_{\text {max }}^{\prime}: \mathrm{PS}_{\mathrm{nt}}$.

Our study demonstrates the feasibility of performing PET studies of pre- and postsynaptic sympathetic function using ${ }^{11} \mathrm{C}$ radiotracers and $\mathrm{MBF}\left({ }^{15} \mathrm{O}\right.$-water $)$ sequentially within $\sim 3.5 \mathrm{~h}$. Performing all imaging in the same session without patient movement minimizes misalignment of cardiac regions on the images and differences in systemic catecholamines that might influence sympathetic function. Our study also demonstrates that radiopharmaceuticals used to measure pre- and postsynaptic sympathetic function with PET do not cause clinically significant hemodynamic effects in healthy subjects or in patients with class II-IV CHF from CAD.

This study has several limitations. The images were recorded over $3.5 \mathrm{~h}$; thus, it is possible that the catecholamine state changed and affected our estimates of sympathetic function. Our prior studies in healthy subjects demonstrated no significant circadian variability in supine resting plasma NE or epinephrine (39). The lack of change in any hemodynamic parameter beyond a slight decrease in resting heart rate during the imaging period suggests that no major alteration occurred in sympathetic function.

Four subjects were taking amiodarone, which theoretically could interfere with ${ }^{11} \mathrm{C}$-mHED kinetics. However, it was recently shown that amiodarone actually improves $\mathrm{NE}$ uptake and retention in rats with chronic heart failure as compared with that of healthy rats (40). Thus, it seems likely that amiodarone did not exaggerate mismatch and potentially could have produced higher ${ }^{11} \mathrm{C}-\mathrm{mHED}$ uptake and a reduced mismatch than might have been otherwise observed.

Eight of our subjects were taking $\beta$-blockers (metoprolol), which could have interfered with our estimate of BAR density; however, none had received any for at least $24 \mathrm{~h}$. The short plasma half-life $(3.5 \mathrm{~h})$ and binding of metoprolol should have cleared the metoprolol from the BAR in $<24 \mathrm{~h}$. Analysis of the subjects on and off $\beta$-blockers suggests that there was no effect but we cannot prove this unequivocally. Anecdotally, we studied 1 patient who had received a $\beta$-blocker within $3 \mathrm{~h}$ of the study and there was no myocardial CGP uptake.
We did not correct the PET images for partial volume in regions in which the LV walls may have been thinned secondary to infarction. We did not have echo data for wall thickness in all subjects and, thus, did not attempt to use wall thickness for partial-volume correction. However, partial volume should not differ greatly between mHED and CGP as both were labeled with ${ }^{11} \mathrm{C}$. We excluded from analysis infracted regions in which the partial-volume effect was likely to be greatest.

Finally, there were few adverse events and the endpoint of transplantation for progressive $\mathrm{CHF}$ is subjective because transplantation depends on availability of an appropriate donor heart and no contraindications. For the patient in whom transplantation was the endpoint, CHF had slowly worsened for several months before the PET study despite optimal medical therapy. His physicians opined that he would have died within a short time or required a mechanical assist device had not a heart become available. The other endpoint of ventricular arrhythmia leading to ICD discharge in 1 and death in the other are objective events, as was the 1 death from progressive CHF. Similar criteria were used by Pietila et al. (38).

\section{CONCLUSION}

This PET study demonstrates that global and regional presynaptic function is decreased in patients with ischemic $\mathrm{CHF}$ as compared with age-matched healthy subjects, whereas postsynaptic BAR density is decreased, although not significantly. This results in a mismatch between preand postsynaptic function that could produce local myocardial conditions that are arrhythmogenic or a marker of worsening CHF. Our preliminary study suggests that patients with the greatest mismatch had more adverse events. We also demonstrated that such PET can be done within a short time period that minimizes the potential for changes in sympathetic function, is clinically acceptable, and does not cause clinically significant hemodynamic changes in patients with moderately severe CHF. These observations are intriguing but require evaluation and confirmation in a much larger patient population before being considered in the clinical management of patients with CHF.

\section{ACKNOWLEDGMENTS}

We thank Marilou Gronka, Katherine Seymour, and Janet May for data collection and image analysis; Barbara Lewellen and the PET suite personnel for image acquisition; Steve Shoner and Minna Zheng for radiochemistry; and Werner Stuetzle, PhD, for statistical support. This research was supported by NIH grants RO1 HL50239 and AG15462. None of the authors has any known conflicts of interest or financial relationships.

\section{REFERENCES}

1. Francis GS, Cohn JN, Johnson G, Rector TS, Goldman S, Simon A. Plasma norepinephrine, plasma renin activity and congestive heart failure. Circulation. 1993;87(6 suppl):VI40-VI48. 
2. Bristow MR, Hershberger RE, Port JD, et al. Beta-adrenergic pathways in nonfailing and failing human ventricular myocardium. Circulation. 1990;82(2 suppl):I12-I25.

3. Bristow MR, Minobe W, Rasmussen R, et al. Beta-adrenergic neuroeffector abnormalities in the failing human heart are produced by local rather than systemic mechanisms. J Clin Invest. 1992;89:803-815.

4. Meredith IT, Eisenhofer G, Lambert GW, Dewar EM, Jennings GL, Esler MD. Cardiac sympathetic nervous activity in congestive heart failure: evidence for increased neuronal norepinephrine release and preserved neuronal uptake. Circulation. 1993;88:136-145.

5. Glowniak JV, Kilty JE, Amara SG, Hoffman BJ, Turner FE. Evaluation of metaiodobenzylguanidine uptake by the norepinephrine, dopamine and serotonin transporters. J Nucl Med. 1993;34:1140-1146.

6. Eisenhofer G, Friberg P, Rundqvist B, et al. Cardiac sympathetic nerve function in congestive heart failure. Circulation. 1996;93:1667-1676.

7. Mardon K, Montagne O, Elbaz N, et al. Uptake-1 carrier downregulates in parallel with the beta-adrenergic receptor desensitization in rat hearts chronically exposed to high levels of circulating norepinephrine: implications for cardiac neuroimaging in human cardiomyopathies. J Nucl Med. 2003;44:1459-1466.

8. Inoue H, Zipes DP. Results of sympathetic denervation in the canine heart: hypersensitivity that may be arrhythmogenic. Circulation. 1987;75:877-887.

9. Inoue H, Zipes DP. Time course of denervation of efferent sympathetic and vagal nerves after occlusion of the coronary artery in the canine heart. Circ Res. 1988; 62:1111-1120.

10. Vracko R, Thorning D, Frederickson RG. Fate of nerve fibers in necrotic, healing, and healed rat myocardium. Lab Invest. 1990;63:490-501.

11. Calkins H, Allman K, Bolling $\mathrm{S}$, et al. Correlation between scintigraphic evidence of regional sympathetic neuronal dysfunction and ventricular refractoriness in the human heart. Circulation. 1993;88:172-179.

12. Voipio-Pulkki L, Vesalainen R, Pietila M, et al. Abnormalities of cardiac autonomic function and ${ }^{11} \mathrm{C}$-hydroxyephedrine PET coincide in heart failure [abstract]. J Am Coll Cardiol. 1996;27(suppl. A):406A.

13. Vesalainen RK, Pietila M, Tahvanainen K, et al. Cardiac positron emission tomography imaging with $\left[{ }^{11} \mathrm{C}\right]$ hydroxyephedrine, a specific tracer for sympathetic nerve endings, and its functional correlates in congestive heart failure. Am J Cardiol. 1999;84:568-574.

14. Link JM, Stratton JR, Levy WC, et al. PET measures of pre- and post-synaptic cardiac beta adrenergic function. Nucl Med Biol. 2003;30:795-803.

15. Ungerer M, Hartmann F, Karoglan M, et al. Regional in vivo and in vitro characterization of autonomic innervation in cardiomyopathic human heart. Circulation. 1998;97:174-180.

16. Bristow MR, Anderson FL, Port JD, et al. Differences in beta-adrenergic neuroeffector mechanisms in ischemic versus idiopathic dilated cardiomyopathy. Circulation. 1991;84:1024-1039.

17. Merlet P, Delforge J, Syrota A, et al. Positron emission tomography with ${ }^{11} \mathrm{C}$ CGP-12177 to assess $\beta$-adrenergic receptor concentration in idiopathic dilated cardiomyopathy. Circulation. 1993;87:1169-1178.

18. Wichter T, Schafers M, Rhodes CG, et al. Abnormalities of cardiac sympathetic innervation in arrhythmogenic right ventricular cardiomyopathy: quantitative assessment of presynaptic norepinephrine reuptake and postsynaptic betaadrenergic receptor density with positron emission tomography. Circulation. 2000;101:1552-1558.

19. Krohn KA, Link JM, Lewellen TK, Risler R, Eenmaa J, Maier M. The use of 50 $\mathrm{MeV}$ protons to produce $\mathrm{C}-11$ and O-15. J Labelled Cmpd Radiopharm. 1986;23:1190-1192.

20. Rosenspire KC, Haka MS, Van Dort ME, et al. Synthesis and preliminary evaluation of carbon-11-meta-hydroxyephedrine: a false transmitter agent for heart neuronal imaging. J Nucl Med. 1990;31:1328-1334.

21. Brady F, Luthra SK, Tochon-Danguy HJ, et al. Asymmetric synthesis of a precursor for the automated radiosynthesis of S-(3'-t-butylamino-2'-hydroxypropoxy)-benzimidazol-2-[ $\left[{ }^{11} \mathrm{C}\right]$ one $\left(\mathrm{S}-\left[{ }^{11} \mathrm{C}\right] \mathrm{CGP} 12177\right)$ as a preferred radioligand for $\beta$-adrenergic receptors. Appl Radiat Isot. 1991;42:621-628.
22. Hammadi A, Crouzel C. Asymmetric synthesis of (2S)- and (2R)-4-(3-tbutylamino-2-hydroxypropoxy)-benzimidazol-2-[ $\left.{ }^{11} \mathrm{C}\right]$-one (S)- and (R)-[ $\left[{ }^{11} \mathrm{C}\right]-$ CGP 12177 from optically active precursors. J Labelled Cmpd Radiopharm. 1991;XXIX:681-690.

23. Link JM, Krohn KA, Clark JC. Production of ${ }^{11} \mathrm{CH}_{3} \mathrm{I}$ by reaction of ${ }^{11} \mathrm{CH}_{3}$ with $\mathrm{I}_{2}$ in a single pass reaction. Nucl Med Biol. 1997;24:93-97.

24. Link JM, Synovec RE, Krohn KA, Caldwell JH. High speed liquid chromatography of phenylethanolamines for the kinetic analysis of $\left[{ }^{11} \mathrm{C}\right]$-meta-hydroxyephedrine and metabolites in plasma. J Chromatogr B Biomed Sci Appl. 1997; 693:31-41.

25. Jones HA, Rhodes CG, Law MP, et al. Rapid analysis for metabolites of $\left[{ }^{11} \mathrm{C}\right]$-labelled drugs: fate of $\left[{ }^{11} \mathrm{C}\right]-\mathrm{S}$-4-(tert-butylamino-2-hydroxypropoxy)benzimidazol-2-one in the dog. J Chromatogr. 1991;570:361-370.

26. Delforge J, Syrota A, Lancon JP, et al. Cardiac beta-adrenergic receptor density measured in vivo using PET, CGP 12177, and a new graphical method. J Nucl Med. 1991;32:739-748.

27. Bergmann SR, Herrero P, Markham J, Weinheiner CJ, Walsh MN. Noninvasive quantitation of myocardial blood flow in human subjects with oxygen-15labeled water and positron emission tomography. J Am Coll Cardiol. 1989;14: 639-652.

28. Caldwell JH, Kroll K, Seymour KM, Link JM, Krohn KA. Quantitation of presynaptic cardiac sympathetic function with ${ }^{11} \mathrm{C}$-meta-hydroxyephedrine (MHED): validation of a blood-tissue exchange model. J Nucl Med. 1998;39: 1327-1334.

29. Delforge J. Correction of a relationship that assesses beta-adrenergic receptor concentration with PET and carbon-11-CGP 12177. J Nucl Med. 1994;35:921.

30. Schwaiger M, Kalff V, Rosenspire K, et al. Noninvasive evaluation of sympathetic nervous system in human heart by positron emission tomography. Circulation. 1990;82:457-464.

31. Allman KC, Wieland DM, Muzik O, DeGrado TR, Wolfe ER, Schwaiger M. Carbon-11 hydroxyephedrine with positron emission tomography for serial assessment of cardiac adrenergic neuronal function after acute myocardial infarction in humans. J Am Coll Cardiol. 1993;22:368-375.

32. Schafers M, Dutka D, Rhodes CG, et al. Myocardial presynaptic and postsynaptic autonomic dysfunction in hypertrophic cardiomyopathy. Circ Res. 1998; $82: 57-62$.

33. Matsunari I, Schricke U, Bengel FM, et al. Extent of cardiac sympathetic neuronal damage is determined by the area of ischemia in patients with acute coronary syndromes. Circulation. 2000;101:2579-2585.

34. Shan K, Bick RJ, Poindexter BJ, et al. Altered adrenergic receptor density in myocardial hibernation in humans: a possible mechanism of depressed myocardial function. Circulation. 2000;102:2599-2606.

35. Kozlovskis PL, Smets MJ, Duncan RC, Bailey BK, Bassett AL, Myerburg RJ. Regional beta-adrenergic receptors and adenylate cyclase activity after healing of myocardial infarction in cats. J Mol Cell Cardiol. 1990;22:311-322.

36. Gordeladze JO, Jynge I, Borchgrevink PC, Sellevold OF. Enhanced responsiveness of the myocardial beta-adrenoceptor-adenylate cyclase system in the perfused rat heart (I). Biosci Rep. 1998;18:229-250.

37. Merlet P, Valette H, Dubois-Rande J, et al. Prognostic value of cardiac metaiodobenzylguanidine imaging in patients with heart failure. $\mathrm{J} \mathrm{Nucl} \mathrm{Med}$. 1992;33:471-477.

38. Pietila M, Malminiemi K, Ukkonen H, et al. Reduced myocardial carbon-11 hydroxyephedrine retention is associated with poor prognosis in chronic heart failure. Eur J Nucl Med. 2001;28:373-376.

39. Chandler WL, Mornin D, Whitten RO, et al. Insulin, cortisol, and catecholamines do not regulate circadian variations in fibrinolytic activity. Thromb Res. 1990;58:1-12.

40. Tachikawa H, Kodama M, Watanabe K, et al. Amiodarone improves cardiac sympathetic nerve function to hold norepinephrine in the heart, prevents left ventricular remodeling, and improves cardiac function in rat dilated cardiomyopathy. Circulation. 2005;111:894-899. 